\title{
Publications: Yoshito Kishi
}

1. "The Catalytic Action of Metal Salts on the Borohydride Reduction of $\alpha$-Bromoketone," T. Goto and Y. Kishi, Tetrahedron Lett. 513 (1961).

2. "The Effect of Metal Salts on the Borohydride Reduction of $3 \beta, 5 \alpha$-Diacetoxy-7 $\alpha$ bromocholestane-6-one," T. Goto and Y. Kishi, J. Chem. Soc. Japan 83, 1135 (1962).

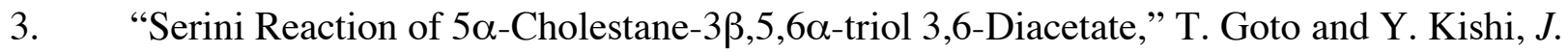
Chem. Soc. Japan 83, 1236 (1962).

4. "Structure of the C9-Base, an Alkaline Degradation Product of Tetrodotoxin," T. Goto, Y. Kishi, and Y. Hirata, Bull. Chem. Soc. Japan 35, 1045 (1962).

5. "Structure of the C8-Base, an Acid Degradation Product of Tetrodotoxin," T. Goto, Y. Kishi, and Y. Hirata, Bull. Chem. Soc. Japan 35, 1244 (1962).

6. "A New Route for the Preparation of Cholestane-3 $3,5 \alpha, 6 \alpha$-triol 3,5-Diacetate from Cholesterol," T. Goto and Y. Kishi, Bull. Chem. Soc. Japan 35, 2044 (1962).

7. "The Structure of Tetrodotoxin,” T. Goto, Y. Kishi, S. Takahashi, and Y. Hirata, Tetrahedron Lett. 2105 (1963).

8. "The Structure and Stereochemistry of Tetrodotoxin," T. Goto, Y. Kishi, S. Takahashi, and Y. Hirata, Tetrahedron Lett. 2115 (1963).

9. “A Revised Molecular Formula of Tetrodotoxin,” T. Goto, S. Takahashi, Y. Kishi, and Y. Hirata, Bull Chem. Soc. Japan 37, 283 (1964).

10. "Further Studies on the Structure of Tetrodotoxin," T. Goto, Y. Kishi, S. Takahashi, and Y. Hirata, Tetrahedron Lett. 779 (1964).

11. "Extraction and Purification of Tetrodotoxin," T. Goto, S. Takahashi, Y. Kishi, and Y. Hirata, J. Chem. Soc. Japan 85, 508 (1964).

12. "Structures of C9-Base, C8-Base, and Oxy-C8-Base, Alkaline and Acid Degradation Products of Tetrodotoxin and its Derivatives," Y. Kishi, H. Taguchi, T. Goto, and Y. Hirata, J. Chem. Soc. Japan 85, 564 (1964).

13. "Structure of Tetrodoic Acid, A Hydrolysis Product of Tetrodotoxin," Y. Kishi, T. Goto, and Y. Hirata, J. Chem. Soc. Japan 85, 572 (1964).

14. "The Structures of Tetrodotoxin and Anhydroepitetrodotoxin," T. Goto, Y. Kishi, S. Takahashi, and Y. Hirata, J. Chem. Soc. Japan 85, 661 (1964). 
15. "Acetylation of Tetrodotoxin," T. Goto, Y. Kishi, S. Takahashi, and Y. Hirata, J. Chem. Soc. Japan 85, 667 (1964).

16. “Aminodesoxytetrodotoxin,” T. Goto, S. Takahashi, Y. Kishi, and Y. Hirata, Tetrahedron Lett. 1831 (1964).

17. “Tetrodotoxin,” T. Goto, Y. Kishi, S. Takahashi, and Y. Hirata, Tetrahedron 21, 2059 (1965).

18. "Cypridina Bioluminescence I. Structure of Cypridina Luciferin," Y. Kishi, T. Goto, Y. Hirata, O. Shimomura, and F. H. Johnson, Tetrahedron Lett. 3427 (1966).

19. “Cypridina Bioluminescence II. Structural Studies of Cypridina Luciferin by Means of a High Resolution Mass Spectrometer and an Amino Acid Analyzer," Y. Kishi, T. Goto, S. Eguchi, Y. Hirata, E. Watanabe, and T. Aoyama, Tetrahedron Lett. 3437 (1966).

20. “Cypridina Bioluminescence III. Total Synthesis of Cypridina Luciferin,” Y. Kishi, T. Goto, S. Inoue, S. Sugiura, and H. Kishimoto, Tetrahedron Lett. 3445 (1966).

21. "The Structure of Cypridina Luciferin," Y. Kishi, T. Goto, Y. Hirata, O. Shimomura, and F. H. Johnson, Bioluminescence in Progress pages pages 89-113 Princeton University Press, Princeton (1966).

22. "Synthesis of Leonurine," Y. Kishi, S. Sugiura, S. Inoue, Y. Hayashi, and T. Goto, Tetrahedron Lett. 637 (1968).

23. "Luciferin and Luciopterin Isolated from the Japanese Firefly, Luciola Cruciata," Y. Kishi, S. Matsuura, S. Inoue, O. Shimomura, and T. Goto, Tetrahedron Lett. 2847 (1968).

24. "Luciferins, Bioluminescent Substances," T. Goto and Y. Kishi, Angew. Chem. 7, 407 (1968).

25. "Structure and Synthesis of Leonurine," S. Sugiura, S. Inoue, Y. Hayashi, Y. Kishi, and T. Goto, Tetrahedron 25, 5155 (1969).

26. "Synthesis of Cypridina Luciferin and Related Compounds. I. Synthesis of 2-Amino-5(3-indoyl)pyrazine," S. Sugiura, S. Inoue, Y. Kishi, and T. Goto, Yakugaku Zasshi 89, 1646 (1969).

27. "Synthesis of Cypridina Luciferin and Related Compounds. II. Synthesis of Etioluciferamine,” S. Sugiura, S. Inoue, Y. Kishi, and T. Goto, Yakugaku Zasshi 89, 1652 (1969).

28. "Synthesis of Cypridina Luciferin and Related Compounds. III. Synthesis of Cypridina Luciferin,” Y. Kishi, S. Sugiura, S. Inoue, and T. Goto, Yakugaku Zasshi 89, 1657 (1969). 
29. "Synthesis and Stereochemistry of Latia Luciferin," F. Nakatsubo, Y. Kishi, and T. Goto, Tetrahedron Lett. 381 (1970).

30. "Synthetic Approach Toward Tetrodotoxin. I. Diels-Alder Reaction of $\alpha$ Oximinoethylbenzoquinones with Butadiene," Y. Kishi, F. Nakatsubo, M. Aratani, T. Goto, S. Inoue, H. Kakoi, and S. Sugiura, Tetrahedron Lett. 5127 (1970).

31. "Synthetic Approach Toward Tetrodotoxin. II. A Stereospecific Synthesis of a Compound Having the Same Six Chiral Centers on the Cyclohexane Ring as Those of Tetrodotoxin," Y. Kishi, F. Nakatsubo, M. Aratani, T. Goto, S. Inoue, and H. Kakoi, Tetrahedron Lett. 5129 (1970).

32. “A Stereoselective Decarboxylation of 1,6-Dimethyl-3-(3'-indol)methyl-3-carboxy-2,5piperazinedione," Y. Kishi, N. Nakatsuka, T. Fukuyama, and T. Goto, Tetrahedron Lett. 4657 (1971).

33. "Synthetic Studies on Echinulin and Relative Compounds, Part I. Acid Catalyzed Amino Claisen Rearrangement of Allyl- and 3,3-Dimethylallylaniline Derivatives," N.

Takamatsu, S. Inoue, and Y. Kishi, Tetrahedron Lett. 4661 (1971).

34. "Synthetic Studies on Echinulin and Related Compounds, Part II. A Stereoselective Total Synthesis of Optically Active Echinulin," N. Takamatsu, S. Inoue, and Y. Kishi, Tetrahedron Lett. 4665 (1971).

35. "New Epoxidation with $m$-Chloroperbenzoic Acid at Elevated Temperatures," Y. Kishi, M. Aratani, H. Tanino, T. Fukuyama, T. Goto, S. Inoue, S. Sugiura, and H. Kakoi, J. C. S. Chem. Comm. 64 (1972).

36. "The Structure Confirmation of the Light-Emitting Moiety of Bioluminescent Jellyfish Aqueorea," Y. Kishi, H. Tanino, and T. Goto, Tetrahedron Lett. 2747 (1972).

37. "Synthetic Studies on Tetrodotoxin and Related Compounds. III. A Stereospecific Synthesis of an Equivalent of Acetylated Tetrodamine," Y. Kishi, M. Aratani, T.

Fukuyama, F. Nakatsubo, T. Goto, S. Inoue, H. Tanino, S. Sugiura, and H. Kakoi, J. Am. Chem. Soc. 94, 9217 (1972).

38. "Synthetic Studies on Tetrodotoxin and Relative Compounds. IV. Stereospecific Total Syntheses of $d l$-Tetrodotoxin," Y. Kishi, T. Fukuyama, M. Aratani, F. Nakatsubo, T. Goto, S. Inoue, H. Tanino, S. Sugiura, and H. Kakoi, J. Am. Chem. Soc. 94, 9219 (1972).

39. "Biosynthesis of Nigrifactin," T. Terashima, E. Idaka, Y. Kishi, and T. Goto, J. C. S. Chem. Comm. 75 (1973). 
40. "Cypridina Bioluminescence. VIII. The Bioluminescence of Cypridina Luciferin Analogs," T. Goto, M. Isobe, D. A. Coviello, Y. Kishi, and S. Inoue, Tetrahedron 29, 2035 (1973).

41. “Aspects of the Mechanism of Bioluminescence," T. Goto, I. Kubota, N. Suzuki, Y. Kishi, and S. Inoue, Chemiluminescence and Bioluminescence pages 325-335 Plenum Publishing, New York (1973).

42. "A New Method for the Synthesis of Epidithiodiketopiperazines," Y. Kishi, T. Fukuyama, and S. Nakatsuka, J. Am. Chem. Soc. 95, 6590 (1973).

43. "A Total Synthesis of Dehydrogliotoxin," Y. Kishi, T. Fukuyama, and S. Nakatsuka, J. Am. Chem. Soc. 95, 6492 (1973).

44. “A Total Synthesis of Sporidesmin A,” Y. Kishi, S. Nakatsuka, T. Fukuyama, and M. Havel, J. Am. Chem. Soc. 95, 6493 (1973).

45. "Synthetic Studies on Tetrodotoxin and Related Compounds. V. The Protecting Group of the C9-Hydroxy Group," H. Tanino, S. Inoue, M. Aratani, and Y. Kishi, Tetrahedron Lett. 335 (1974).

46. “A Total Synthesis of $d l$-Sporidesmin B,” S. Nakatsuka, T. Fukuyama, and Y. Kishi, Tetrahedron Lett. 1549 (1974).

47. "Synthetic Study of Puffer Fish Poison, Tetrodotoxin," Y. Kishi, J. Syn. Org. Chem. Jap. 32,855 (1974).

48. “Cypridina Bioluminescence. IX. Tautomeric Structures of 2-Methyl-3,7dihydroimidazo[1,2-a]pyrazin-3-one, 2-Methyl-3-aminoimidazo[1,2-a]-pyrazine and Their Derivatives in Neutral and Acidic Media," T. Goto, M. Isobe, Y. Kishi, S. Inoue, and S. Sugiura, Tetrahedron 31, 939 (1975).

49. "X-Ray Structure Determination of 3,6-p-Anisylidenedithio-3-ethyl-N,N'dimethylpiperazine-2,5-dione," K. Sasaki, T. Fukuyama, S. Nakatsuka, and Y. Kishi, J. C. S. Chem. Comm. 542 (1975).

50. "Synthetic Studies on Histrionicotoxins. I. A Stereocontrolled Synthesis of $( \pm)-$ Perhydrohistrionicotoxin," M. Aratani, L. V. Dunkerton, T. Fukuyama, Y. Kishi, H. Kakoi, S. Sugiura, and S. Inoue, J. Org. Chem. 40, 2009 (1975).

51. "Synthetic Studies on Histrionicotoxins. II. A Practical Synthetic Route to ( \pm )-Perhydroand $( \pm)$-Octahydrohistrionicotoxin," T. Fukuyama, L. V. Dunkerton, M. Aratani, and Y. Kishi, J. Org. Chem. 40, 2011 (1975).

52. "Biogenetic-Type Synthesis of Penicillin-Cephalosporin Antibiotics. I. A Stereocontrolled Synthesis of the Penam- and Cephem-Ring Systems from an Acyclic 
Tripeptide Equivalent," S. Nakatsuka, H. Tanino, and Y. Kishi, J. Am. Chem. Soc. 97, 5008 (1975).

53. "Biogenetic-Type Synthesis of Penicillin-Cephalosporin Antibiotics. II. An Oxidative Cyclization Route to $\beta$-Lactam Thiazoline Derivatives," S. Nakatsuka, H. Tanino, and Y. Kishi, J. Am. Chem. Soc. 97, 5010 (1975).

54. "Synthetic Studies in the Field of Natural Products," Y. Kishi, Pure Appl. Chem. 43, 423 (1975).

55. "Hydrolytic Cleavage of Thiazoline Sulfoxides by a Radical Chain Process Selective Transformation of Cooper's $\beta$-Lactam Thiazolines into Penicillin Sulfoxides," H. Tanino, S. Nakatsuka, and Y Kishi, Tetrahedron Lett. 581 (1976).

56. "New Conditions for Controlled Claisen Rearrangements of Kallyl Aryl Ethers," D. S. Karanewsky and Y. Kishi, J. Org. Chem. 41, 3026 (1976).

57. “A Total Synthesis of Gliotoxin," T. Fukuyama and Y. Kishi, J. Am. Chem. Soc. 98, 6723 (1976).

58. “A New Synthesis of Epidithiapiperazinediones,” T. Fukuyama, S. Nakatsuka, and Y. Kishi, Tetrahedron Lett. 3393 (1976).

59. "A Promising Cyclization Reaction to Construct the Saxitoxin Ring System," H. Taguchi, H. Yazawa, J. F. Arnett, and Y. Kishi, Tetrahedron Lett. 627 (1977).

60. “A Stereospecific Total Synthesis of $d l$-Saxitoxin,” H. Tanino, T. Nakata, T. Kaneko, and Y. Kishi, J. Am. Chem. Soc. 99, 2818 (1977).

61. "Synthetic Studies on Echinulin and Related Natural Products. I. Acid-Catalyzed Amino-Claisen Rearrangement of N-Allylaniline and N,N'-Diallylaniline Derivatives," S. Inoue, N. Takamatsu, and Y. Kishi, Yakugaku Zasshi 97, 553 (1977).

62. "Synthetic Studies on Echinulin and Related Products. II. A Total Synthesis of Echinulin," S. Inoue, N. Takamatsu, and Y. Kishi, Yakugaku Zasshi 97, 558 (1977).

63. "Synthetic Studies on Echinulin and Related Products. III. A Total Synthesis of Neoechinulin," S. Inoue, N. Takamatsu, and Y. Kishi, Yakugaku Zasshi 97, 564 (1977).

64. "Synthetic Studies on Echinulin and Related Products. IV. Isolation, Structure and Synthesis of Flavoglaucin-Auroglaucin Type Natural Products Isolated from Aspergillus amstelodami," S. Inoue, K. Hashizume, N. Takamatsu, H. Nagano, and Y. Kishi, Yakugaku Zasshi 97, 569 (1977).

65. "Synthetic Studies on Echinulin and Related Products. V. Isolation Structure and Synthesis of Echinulin-Neoechinulin type Alkaloids Isolated from Aspergillus 
amstelodami," S. Inoue, J. Murata, N. Takamatsu, H. Nagano, and Y. Kishi, Yakugaku Zasshi 97, 576 (1977).

66. "Synthetic Studies on Echinulin and Related Products. VI. Structure and Synthesis of Aurechinulin," S. Inoue, N. Takamatsu, K. Hashizume, and Y. Kishi, Yakugaku Zasshi 97, 582 (1977).

67. "Synthetic Studies toward Mitomycins. I. Total Synthesis of Deiminomitomycin A," F. Nakatsubo, A. J. Cocuzza, D. E. Keeley, and Y. Kishi, J. Am. Chem. Soc. 99, 4835 (1977).

68. "Synthetic Studies Toward Mitomycins. II. Total Synthesis of $d l$-Porfiromycin," F. Nakatsubo, T. Fukuyama, A. J. Cocuzza, and Y. Kishi, J. Am. Chem. Soc. 99, 8115 (1977).

69. "Synthetic Studies Toward Mitomycins. III. Total Syntheses of Mitomycins A and C," T. Fukuyama, F. Nakatsubo, A. J. Cocuzza, and Y. Kishi, Tetrahedron Lett. 4295 (1977).

70. "The Stereospecific Synthesis of Tetrahydroaustamide," A. J. Hutchison and Y. Kishi, Tetrahedron Lett. 539 (1977).

71. “Total Synthesis of Lasalocid A,” T. Nakata, G. Schmid, B. Vranesic, M. Okigawa, T. Smith-Palmer, and Y. Kishi, J. Am. Chem. Soc. 100, 2933 (1978).

72. "Synthetic Studies on Polyether Antibiotics. II. Stereocontrolled Syntheses of Epoxides of Bishomoallylic alcohols," T. Fukuyama, B. Vranesic, D. P. Negri, and Y. Kishi, Tetrahedron Lett. 2741 (1978).

73. "Synthetic Studies on Polyether Antibiotics. III. A Stereocontrolled Synthesis of Isolasalocid Ketone from Acyclic Precursors," T. Nakata and Y. Kishi, Tetrahedron Lett. 2745 (1978).

74. "Total Synthesis of Monensin. I. Stereocontrolled Synthesis of the Left Half of Monensin," G. Schmid, T. Fukuyama, K. Akasaka, and Y. Kishi, J. Am. Chem. Soc. 101, 259 (1979).

75. "Total Synthesis of Monensin. II. Stereocontrolled Synthesis of the Right Half of Monensin," T. Fukuyama, C.-L. J. Wang, and Y. Kishi, J. Am. Chem. Soc. 101, 260 (1979).

76. “Total Synthesis of Monensin. III. Stereocontrolled Synthesis of Monensin,” T. Fukuyama, K. Akasaka, D. S. Karanewsky, C.-L. J. Wang, G. Schmid, and Y. Kishi, J. Am. Chem. Soc. 101, 262 (1979).

77. “The Stereospecific Total Synthesis of $d l$-Austamide,” A. J. Hutchison and Y. Kishi, J. Am. Chem. Soc. 101, 6786 (1979). 
78. "Stereo- and Regioselective Methods for the Synthesis of Three Consecutive Asymmetric Units Found in Many Natural Products," M. R. Johnson, T. Nakata, and Y. Kishi, Tetrahedron Lett. 4343 (1979).

79. “Cooperative Effect by a Hydroxy and Ether Oxygen in Epoxidation with a Peracid," M. R. Johnson and Y. Kishi, Tetrahedron Lett. 4347 (1979).

80. “The Total Synthesis of Mitomycins,” Y. Kishi, J. Nat. Prod. 42, 549 (1979).

81. “The Total Synthesis of Monensin," Y. Kishi, Lectures in Heterocyclic Chemistry Vol. $V$, pages 95-109 HeteroCorp., Provo (1980).

82. "Recent Developments in the Chemistry of Natural Products," Y. Kishi, Aldrichimica Acta 13, 23 (1980).

83. “Total Synthesis of $d l$-Saxitoxin,” Y. Kishi, Heterocycles 14, 1477 (1980).

84. "Further Studies on Stereospecific Epoxidation of Allylic Alcohols," I. Hasan and Y. Kishi, Tetrahedron Lett. 21, 4229 (1980).

85. "Total Synthesis of ( \pm -Gephyrotoxin,” R. Fujimoto, Y. Kishi, and J. F. Blount, J. Am. Chem. Soc. 102, 7154 (1980).

86. "Total Synthesis of Rifamycins. 1. Stereocontrolled Synthesis of the Aliphatic Building Block," H. Nagaoka, W. Rutsch, G. Schmid, H. Iio, M. R. Johnson, and Y. Kishi, J. Am. Chem. Soc. 102, 7962 (1980).

87. “Total Synthesis of Rifamycins. 2. Total Synthesis of Racemic Rifamycin S," H. Iio, H. Nagaoka, and Y. Kishi, J. Am. Chem. Soc. 102, 7965 (1980).

88. "A Synthesis of the Aromatic Segment of Rifamycin S," H. Nagaoka, G. Schmid, H. Iio, and Y. Kishi, Tetrahedron Lett. 22, 899 (1981).

89. “Total Synthesis of Rifamycin S,” Y. Kishi, Pure Appl. Chem. 53, 1163 (1981).

90. "Total Synthesis of Gliotoxin, Dehydrogliotoxin and Hyalodendrin," T. Fukuyama, S. Nakatsuka, and Y. Kishi, Tetrahedron 37, 2045 (1981).

91. “A Model Study for the Biomimetic-type Synthesis of Rifamycin S," H. Iio, H. Nagaoka, and Y. Kishi, Tetrahedron Lett. 22, 2451 (1981).

92. "Practical Total Synthesis of ( \pm -Aklavinone and Total Synthesis of Aklavin," B. A. Pearlman, J. M. McNamara, I. Hasan, S. Hatakeyama, H. Sekizaki, and Y. Kishi, J. Am. Chem. Soc. 103, 4248 (1981). 
93. "On the Absolute Configuration of Gephyrotoxin," R. Fujimoto and Y. Kishi, Tetrahedron Lett. 22, 4197 (1981).

94. "Further Synthetic Studies on Rifamycin S," H. Nagaoka and Y. Kishi, Tetrahedron 37, 3873 (1981).

95. “Total Synthesis of Polyether Antibiotics,” T. Nakata and Y. Kishi, Kagaku Sosetsu 31, 243 (1981).

96. “Total Synthesis of Polyether Antibiotics Narasin and Salinomycin,” Y. Kishi, S. Hatakeyama, and M. D. Lewis, Frontiers in Chemistry (28th IUPAC Congress) pages 287-304 Pergamon, Oxford (1982).

97. "Stereocontrolled Synthesis of D. Pentitols, 2-Amino-2-deoxy-D-pentitols, and 2-DeoxyD-pentitols,” N. Minami, S. S. Ko, and Y. Kishi, J. Am. Chem. Soc. 104, 1109 (1982).

98. "Further Studies on Chromium(II)-Mediated Homoallylic Alcohol Syntheses," M. D. Lewis and Y. Kishi, Tetrahedron Lett. 23, 2343 (1982).

99. "Reductive Ring Openings of Allylic Alcohol Epoxides," J. M. Finan and Y. Kishi, Tetrahedron Lett. 23, 2719 (1982).

100. "Highly Stereoselective Approaches to $\alpha$ - and $\beta$-C-Glycopyranosides," M. D. Lewis, J. K. Cha, and Y. Kishi, J. Am. Chem. Soc. 104, 4976 (1982).

101. "Stereochemistry of Palytoxin. Part I. C.85-C.115 Segment," L. L. Klein, W. W. McWhorter, Jr., S. S. Ko, K.-P. Pfaff, Y. Kishi, D. Uemura, and Y. Hirata, J. Am. Chem. Soc. 104, 7362 (1982).

102. "Stereochemistry of Palytoxin. Part II. C.1-C.6, C.47-C.74 and C.77-C.83 Segments," S. S. Ko, J. M. Finan, M. Yonaga, Y. Kishi, D. Uemura, and Y. Hirata, J. Am. Chem. Soc. 104, 7364 (1982).

103. "Stereochemistry of Palytoxin. Part III. C.7-C.51 Segment,” H. Fujioka, W. J. Christ, J.K. Cha, J. Leder, Y. Kishi, D. Uemura, and Y. Hirata, J. Am. Chem. Soc. 104, 7367 (1982).

104. "Stereochemistry of Palytoxin. Part IV. Complete Structure," J.-K. Cha, W. J. Christ, J. M. Finan, H. Fujioka, Y. Kishi, L. L. Klein, S. S. Ko, J. Leder, W. W. McWhorter, Jr., K.-P. Pfaff, M. Yonaga, D. Uemura, and Y. Hirata, J. Am. Chem Soc. 104, 7369 (1982).

105. "Synthetic Studies on Palytoxin. Stereocontrolled, Practical Synthesis of the C.101C.115 Segment," S. S. Ko, L. L. Klein, K.-P. Pfaff, and Y. Kishi, Tetrahedron Lett. 23, 4415 (1982). 
106. "Practical Asymmetric Synthesis of Aklavinone," J. M. McNamara and Y. Kishi, J. Am. Chem. Soc. 104, 7371 (1982).

107. "Practical Asymmetric Syntheses of 11-Deoxydaunomycinone and Related Compounds," H. Sekizaki, M. Jung, J. M. McNamara, and Y. Kishi, J. Am. Chem. Soc. 104, 7372 (1982).

108. "Synthetic Studies on Palytoxin. Stereocontrolled Practical Synthesis of the C.23-C.37 Segment," J. Leder, H. Fujioka, and Y. Kishi, Tetrahedron Lett. 24, 1463 (1983).

109. "Stereochemistry of Palytoxin," Y. Kishi, Current Trends in Organic Synthesis (IUPAC) pages 115-130 Pergamon, Oxford (1983).

110. "Synthetic Studies of Palytoxin. Stereocontrolled Practical Synthesis of the C.85-C.98 Segment,” W. W. McWhorter, Jr., S. H. Kang, and Y. Kishi, Tetrahedron Lett. 24, 2243 (1983).

111. "An Improved Procedure for the Blaise Reaction: A Short, Practical Route to the Key Intermediates of the Saxitoxin Synthesis," S. M. Hannick and Y. Kishi, J. Org. Chem. 48, 3833 (1983).

112. "On Stereochemistry of Osmium Tetroxide Oxidation of Allylic Alcohol Systems: Empirical Rule,” J. K. Cha, W. J. Christ, and Y. Kishi, Tetrahedron Lett. 24, 3943 (1983).

113. "On Stereochemistry of Osmium Tetroxide Oxidation of Allylic Alcohol Systems: Examples,” W. J. Christ, J. K. Cha, and Y. Kishi, Tetrahedron Lett. 24, 3947 (1983).

114. "Chemical Synthesis," Y. Kishi, Polyether Antibiotics, Naturally Occuring Acid Ionophores Vol. 2: Chemistry, pages 1-50 Marcel Dekker, New York (1983).

115. "Palytoxin," Y. Kishi, Selectivity - A Goal for Synthetic Efficiency pages 99-119 Verlag Chemie, Weinheim (1984).

116. "On Stereochemistry of Osmium Tetraoxide Oxidation of Allylic Alcohol Systems," J. K. Cha, W. J. Christ, and Y. Kishi, Tetrahedron 40, 2247 (1984).

117. "Practical Asymmetric Synthesis of Aklavinone," J. M. McNamara and Y. Kishi, Tetrahedron 40, 4685 (1984).

118. "Synthesis of Mono and Unsymmetrical Bis Ortho Esters of scyllo-Inositol," H. W. Lee and Y. Kishi, J. Org. Chem. 50, 4402 (1985).

119. “A Total Synthesis of $d, l$-histrionicotoxin,” S. C. Carey, M. Arantani and Y. Kishi, Tetrahedron Lett. 26, 5887 (1985). 
120. "Natural Product Synthesis: Palytoxin,” Y. Kishi, W. J. Christ, and M. Taniguchi, Natural Products and Biological Activities pages 87-98 Tokyo University Press, Tokyo (1986).

121. "Catalytic Effect of Nickel(II) Chloride and Palladium(II) Acetate on Cr(II)-Mediated Coupling Reaction of Iodoolefins with Aldehydes," H. Jin, J-I. Uenishi, W. J. Christ, and Y. Kishi, J. Am. Chem. Soc. 108, 5644 (1986).

122. “Terminal Expoxidation of Farnesate Attached to Helical Peptides," K.-H. Budt, J.-M. Vatele, and Y. Kishi, J. Am. Chem. Soc. 108, 6080 (1986).

123. “A Practical Synthesis of Trans-Iodoolefins,” S. H. Cheon, W. J. Christ, L. D. Hawkins, H. Jin, Y. Kishi, and M. Taniguchi, Tetrahedron Lett. 39, 4759 (1986).

124. “ $\beta$-Halovinyl Ketones: Synthesis from Acetylenic Ketones,” M. Taniguchi, S. Kobayashi, M. Nakagawa, T. Hino, and Y. Kishi, Tetrahedron Lett. 39, 4763 (1986).

125. "Aldol Reaction of Allenolates Generated Via 1,4-Addition of Iodide Anion or Its Equivalent to $\alpha, \beta$-Acetylenic Ketones," M. Taniguchi, T. Hino, and Y. Kishi, Tetrahedron Lett. 39, 4767 (1986).

126. "Structure of the Functional Part of Photoprotein Aequorin," B. Musicki, Y. Kishi, and O. Shimomura, J. Chem. Soc., Chem. Commun. 1566 (1986).

127. "A New, Efficient Synthesis of the Left Half of Narasin," J. A. Tino, M. D. Lewis, and Y. Kishi, Heterocycles 25, 97 (1987).

128. "Synthesis of C-Disaccharides," S. A. Babirad, Y. Wang, and Y. Kishi, J. Org. Chem. 52, 1370 (1987).

129. “A Total Synthesis of Polyether Antibiotic (-)-A23187 (Calcimycin),” D. P. Negri and Y. Kishi, Tetrahedron Lett. 28, 1068 (1987).

130. "Synthetic Studies Towards Halichondrins," T. D. Aicher and Y. Kishi, Tetrahedron Lett. 28, 3463 (1987).

131. "Dramatic Rate-Enhancement of Suzuki Diene Synthesis," J.-I. Uenishi, J.-M. Beau, R. W. Armstrong, and Y. Kishi, J. Am. Chem. Soc. 109, 4756 (1987).

132. "Total Synthesis of Debromoaplysiatoxin and Aplysiatoxin,” P.-U. Park, C. A. Broka, B. F. Johnson, and Y. Kishi, J. Am. Chem. Soc. 109, 6205 (1987).

133. "Preferred conformation of $C$-Glycosides. 1. Conformational Similarity of Glycosides and Corresponding C-Glycosides," T.-C. Wu, P. G. Geokjian, and Y. Kishi, J. Org. Chem. 52, 4819 (1987). 
134. "Preferred Conformation of $C$-Glycosides. 2. Preferred Conformation of Carbon Analogues of Isomatose," T.-C. Wu, H.-Y. Kang, P. G. Geokjian, and Y. Kishi, J. Org. Chem. 52, 4823 (1987).

135. "Preferred Conformation of $C$-Glycosides. 3. Preferred Conformation of Carbon Analogues of Gentiobiose," S. A. Babirad, Y. Wang, P. G. Geokjian, and Y. Kishi, J. Org. Chem. 52, 4825 (1987).

136. "Synthetic Studies on Palytoxin," Y. Kishi, Chemica Scripta 27, 573 (1987).

137. "Influence of Secondary Structure (Helical Conformation) on Stereoselectivity in Peptide Couplings,” T. Li, K.-H. Budt, and Y. Kishi, J. Chem. Soc., Chem. Commun. 1817 (1987).

138. "Semi-synthetic Aequorin: An Improved Tool for the Measurement of Calcium Concentration,” O. Shimomura, B. Musicki, and Y. Kishi, Biochem. J. 251 (1988).

139. "Structure of the Light-Emitter in Krill (Euphausia pacifica) Bioluminescence," H. Nakamura, B. Musicki, Y. Kishi, and O. Shimomura, J. Am. Chem. Soc. 110, 2683 (1988).

140. "Panal: A Possible Precursor of Fungal Luciferin,” H. Nakamura, Y. Kishi, and O. Shimomura, Tetrahedron 44, 1597 (1988).

141. "Synthesis of C-Sucrose," U. C. Dyer and Y. Kishi, J. Org. Chem. 53, 3383 (1988).

142. "Preferred Conformation of $C$-Glycosides. 4. Importance of 1,3-Diaxial-like Interactions Around the Nonglycosidic Bond: Prediction and Experimental Proof," Y. Wang, P. G. Goekjian, D. M. Ryckman, and Y. Kishi, J. Org. Chem. 53, 4151 (1988).

143. "Synthetic Studies on Ophiobolins," M. Rowley and Y. Kishi, Tetrahedron Lett. 29, 4909 (1988).

144. "Preferred Conformation of $C$-Glycosides. 5. Experimental Support for the Conformational Similarity between $C$ - and $O$-Disaccharides," W. H. Miller, D. M. Ryckman, P. G. Goekjian, Y. Wang, and Y. Kishi, J. Org. Chem. 53, 5580 (1988).

145. “Natural Product Synthesis: Palytoxin,” Y. Kishi, Chemtracts 1, 253 (1988).

146. "Natural Product Synthesis: Palytoxin,” Y. Kishi, Pure Appl. Chem. 61, 313 (1989).

147. "A Total Synthesis of (+)-Ophiobolin C," M. Rowley, M. Tsukamoto, and Y. Kishi, J. Am. Chem. Soc. 111, 2735 (1989).

148. "Semi-Synthetic Aequorin: Improved Sensitivity to Calcium Ion," O. Shimomura, B. Musicki, and Y. Kishi, Biochem J. 261, 913 (1989). 
149. "Structure of Dinoflagellate Luciferin and Its Enzymatic and Non-enzymatic Airoxidation Products," H. Nakamura, Y. Kishi, O. Shimomura, D. Morse, and J. W. Hastings, J. Am. Chem. Soc. 111, 7607 (1989).

150. “Total Synthesis of a Fully Protected Palytoxin Carboxylic Acid,” R. W. Armstrong, J.M. Beau, S. H. Cheon, W. J. Christ, H. Fujioka, W.-H. Ham, L. D. Hawkins, H. Jin, S. H. Kang, Y. Kishi, M. J. Martinelli, W. W. McWhorter, Jr., M. Mizuno, M. Nakata, A. E. Stutz, F. X. Talamas, M. Taniguchi, J. A. Tino, K. Ueda, J. Uenishi, J. B. White, and M. Yonaga, J. Am. Chem. Soc. 111, 7525 (1989).

151. "Total Synthesis of Palytoxin Carboxylic Acid and Palytoxin Amide," R. W. Armstrong, J.-M. Beau, S. H. Cheon, W. J. Christ, H. Fujioka, W.-H. Ham, L. D. Hawkins, H. Jin, S. H. Kang, Y. Kishi, M. J. Martinelli, W. W. McWhorter, Jr., M. Mizuno, M. Nakata, A. E. Stutz, F. X. Talamas, M. Taniguchi, J. A. Tino, K. Ueda, J. Uenishi, J. B. White, and M. Yonaga, J. Am. Chem. Soc. 111, 7530 (1989).

152. "Structural basis of Protein Kinase C Activation by Tumor Promoters," H. Nakamura, Y. Kishi, M. A. Pajares, and R. R. Rando, Proc. Natl. Acad. Sci., USA 86, 9672 (1989).

153. "Total Synthesis of Mycalamides A and B," C. Y. Hong and Y. Kishi, J. Org. Chem. 55, 4242 (1990).

154. "Recombinant Aequorin and Recombinant Semi-synthetic Aequorins: Cellular Calcium Ion Indicators," O. Shimomura, S. Inouye, B. Musicki, and Y. Kishi, Biochem J. 270, 309 (1990).

155. "From Luc and Phot Genes to the Hospital Bed," A. K. Campbell, G. Sala-Newby, P. Aston, N. Kalsheka, Y. Kishi, and O. Shimomura, J. Bioluminescence and Chemiluminescence 5, 131 (1990).

156. "The stereochemical requirement for protein kinase $\mathrm{C}$ activation by 3-Methyldiglycerides matches that found in naturally occurring tumor promoters aplysiatoxins," F. Kong, Y. Kishi, D. Perez-Sala, and R. R. Rando, FEBS Letters 274, 203 (1990).

157. "Gonyauline: a Novel Endogenous Substance Shortening the Period of the Circadian Clock of a Unicellular Alga,” T. Roenneberg, H. Nakamura, L. D. Cranmer III, K. Ryan, Y. Kishi, and J. Woodland Hastings, Experientia 47, 103 (1991).

158. "The Pharmacophore of Debromoaplysiatoxin Responsible for Protein Kinase C Activation,” F. Kong, Y. Kishi, D. Perez-Sala, and R. R. Rando, Proc. Natl. Acad. Sci., USA 88, 1973 (1991).

159. "Preferred Conformation of $C$-Glycosides. 6. Conformational Similarity of Glycosides and Corresponding C-Glycosides," P.G. Goekjian, T.-C. Wu, and Y. Kishi, J. Org. Chem. 56, 6412 (1991). 
160. "Preferred Conformation of $C$-Glycosides. 7. Preferred Conformation of Carbon Analogues of Isomaltose and Gentiobiose,” P.G. Goekjian, T.-C. Wu, H.-Y. Kang, and Y. Kishi, J. Org. Chem. 56, 6422 (1991).

161. "Palytoxin Induces an Increase in the Cation Conductance of Red Cells," M. T. Tosteson, J. A. Halperin, Y. Kishi, and D. C. Tosteson, J. Gen. Physiol. 98, 969 (1991).

162. “Total Synthesis of Onnamide A,” C. Y. Hong and Y. Kishi J. Am. Chem. Soc. 113, 9693 (1991).

163. "Preferred Conformation of $C$-Glycosides. 8. Synthesis of 1,4-Linked Carbon Disaccharides,” Y, Wang, S. A. Babirad, and Y. Kishi, J. Org. Chem. 57, 468 (1992).

164. "Preferred Conformation of $C$-Glycosides. 9. Conformational Analysis of 1,4-Linked Carbon Disaccharides," Y. Wang, P. G. Goekjian, D. M. Ryckman, W. H. Miller, S. A. Babirad, and Y. Kishi, J. Org. Chem. 57, 482 (1992).

165. "Preferred Conformation of $C$-Glycosides. 10. Synthesis and Conformational Analysis of Carbon Trisaccharides," T. Haneda, P. G. Goekjian, S. H. Kim, and Y. Kishi, J. Org. Chem. 57, 490 (1992).

166. “Applications of $\mathrm{Ni}(\mathrm{II}) / \mathrm{Cr}$ (II)-Mediated Coupling Reactions to Natural Products Synthesis," Y. Kishi, Pure Appl. Chem. 64, 343 (1992).

167. "Synthetic Studies Towards Halichondrins: Synthesis of the C.27-C.38 Segment," T. D. Aicher, K. R. Buszek, F. G. Fang, C. J. Forsyth, S. H. Jung, Y. Kishi, and P. M. Scola Tetrahedron Lett. 33, 1549 (1992).

168. "Synthetic Studies Towards Halichondrins: Synthesis of the Left Half of Halichondrins," K. R. Buszek, F. G. Fang, C. J. Forsyth, S. H. Jung, Y. Kishi, P. M. Scola, and S. K. Yoon Tetrahedron Lett. 33, 1553 (1992).

169. "Synthetic Studies Towards Halichondrins: Synthesis of the Left Halves of Norhalichondrins and Homohalichondrins," F. G. Fang, Y. Kishi, M. C. Matelich, and P. M. Scola Tetrahedron Lett. 33, 1557 (1992).

170. "Total Synthesis of Halichondrin B and Norhalichondrin B," T. D. Aicher, K. R. Buszek, F. G. Fang, C. J. Forsyth, S. H. Jung, Y. Kishi, M. C. Matelich, P. M. Scola, D. M. Spero, and S. K. Yoon, J. Am. Chem. Soc. 114, 3162 (1992).

171. "Structural Basis of Protein Kinase C Activation by Diacylglycerols and Tumor Promoters," Robert R. Rando and Yoshito Kishi, Biochemisry 31, 2211 (1992).

172. "Enantioselective Total Synthesis of Decarbamoyl Saxitoxin," C. Y. Hong and Y. Kishi J. Am. Chem. Soc. 114, 7001 (1992). 
173. "The Structural Basis of Protein Kinase C Activation by Diacylglycerols and Tumor Promoters", Robert R. Rando and Yoshito Kishi, Protein Kinase C current concepts and future perspectives pages 41-61, Ellis Horwood, New York (1992).

174. "Preferred Conformation of $C$-Glycosides. 11. $C$-Surcrose: New Practical Synthesis, Structural Reassignment, and Solid-State and Solution Conformation of its Octaacetate", D. J. O'Leary and Y. Kishi, J. Org. Chem. 58, 304 (1993).

175. "Preferred Solution Conformation of Marine Natural Product Palytoxin and of $C$ Glycosides and Their Parent Glycosides," Y. Kishi, Pure Appl. Chem. 65, 771 (1993).

176. "Structure and Non-Enzymatic Light Emission of Two Luciferin Precursors Iolated from the Luminous Mushroom Panellus Stipticus," O. Shimomura, Shigeki Satoh, and Y. Kishi, Bioluminescence and Chemiluminescence 8, 201 (1993).

177. "Light-Emitting Properties of Recombinant Semi-Synthetic Aequorins and Recombinant Flurorescein-Conjugated Aequorin for Measuring Cellular Calcium," O. Shimomura, B. Musicki, Y. Kishi, and S. Inouye, "Cell Calcium" 14, 373 (1993).

178. "Chiral Analogs of Enterobactin with Hydrophilic or Lipophilic Properties", Bruno Tse and Yoshito Kishi, J. Am. Chem. Soc. 115, 7892 (1993).

179. "Synthetic Studies Toward the Taxane Class of Natural Products", Michael H. Kress, Rejean Ruel, William H. Miller, and Yoshito Kishi, Tetrahedron Lett. 34, 5999 (1993).

180. "Investigations of the Intramolecular $\mathrm{Ni}(\mathrm{II}) / \mathrm{Cr}(\mathrm{II})$-Mediated Coupling Reaction: Application to the Taxane Ring System", Michael H. Kress, Rejean Ruel, William H. Miller, and Yoshito Kishi, Tetrahedron Lett. 34, 6003 (1993).

181. "The relative rate of aequorin regeneration from apoaequorin and coelenterazine analogues", Osamu Shimomura, Yoshito Kishi and Satoshi Inouye, Biochem. J. 296, 549 (1993).

182. "Synthetic Studies on Halichondrins: A New Practical Synthesis of the C.1-C.12Segment", James J.-W. Duan and Yoshito Kishi, Tetrahedron Lett. 34, 7541 (1993).

183. "A Concise Synthesis of Enantiomerically Pure Taxane $C$-Ring via the [2,3] Wittig Rearrangement", Michael H. Kress, Brian F. Kaller, and Yoshito Kishi, Tetrahedron Lett. 34, 8047 (1993).

184. "Preferred Conformation of $C$-Glycosides. 12. Synthesis and Conformational Analysis of $\alpha, \alpha-, \alpha, \beta$ - and $\beta, \beta-C$-Trehaloses", Alexander Wei and Yoshito Kishi, J. Org. Chem. 59, 88 (1994). 
185. "Novel Structure Elucidation of AAL Toxin $\mathrm{T}_{\mathrm{A}}$ Backbone", Craig D. Boyle, JeanChristophe Harmange, and Yoshito Kishi, J. Am. Chem. Soc. 116, 4995 (1994).

186. " $C$-Sucrose vs. $O$-Sucrose: Different Conformational Behavior in Methanol Solutions

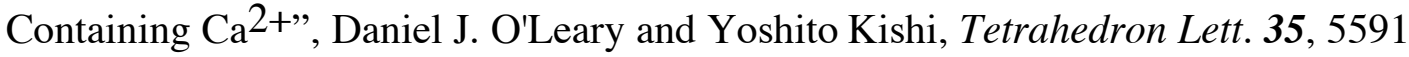
(1994).

187. "Extension of the Criegee Rearrangement: Synthesis of Enol Ethers from Secondary Allylic Hydroperoxides", Richard M. Goodman and Yoshito Kishi, J. Org. Chem. 59, 5125 (1994).

188. "Relative and Absolute Stereochemistry of the Fumonisin $B_{2}$ Backbone", JeanChristophe Harmange, Craig D. Boyle, and Yoshito Kishi, Tetrahedron Lett. 35, 6819 (1994).

189. "Preferred Conformation of $C$-Glycosides. 13. A Comparison of the Conformational Behavior of Several $C$-, $N$-, and $O$-Furanosides", Daniel J. O'Leary and Yoshito Kishi, $J$. Org. Chem. 59, 6629 (1994).

190. "Synthetic Studies Towards Batrachotoxin 1. A Furan-based Intramolecular Diels-Alder Route To Construct The A-D Ring System", Timothy J. Grinsteiner and Yoshito Kishi, Tetrahedron Lett. 35, 8333 (1994).

191. "Synthetic Studies Towards Batrachotoxin 2. Formation Of The Oxazepane Ring System Via A Michael Reaction", Timothy J. Grinsteiner and Yoshito Kishi, Tetrahedron Lett. 35, 8337 (1994).

192. "Synthesis of Palytoxin from Palytoxin Carboxylic Acid", Edward M. Suh and Yoshito Kishi, J. Am. Chem. Soc. 116, 11205 (1994).

193. "Dinoflagellate Bioluminescence: The Chromophore of Dinoflagellate Luciferin", Milan N. Stojanovic and Yoshito Kishi, Tetrahedron Lett. 35, 9343 (1994).

194. "Dinoflagellate Bioluminescence: Chemical Behaviour of the Chromophore towards Oxidants", Milan N. Stojanovic and Yoshito Kishi, Tetrahedron Lett. 35, 9347 (1994).

195. "Conformationally Rigid Tricyclic Tripods: Synthesis and Application to Preparation of Enterobactin Analogs", Bruno Tse and Yoshito Kishi, J. Org. Chem. 59, 7807 (1994).

196. "E5531, a Pure Endotoxin Antagonist of High Potency", William J. Christ, Osamu Asano, Andrea L. C. Robidoux, Michel Perez, Yuan Wang, Gloria R. Dubuc, Wendy E. Gavin, Lynn D. Hawkins, Pamela D. McGuinness, Maureen A. Mullarkey, Michael D. Lewis, Yoshito Kishi, Tsutomu Kawata, John R. Bristol, Jeffrey R. Rose, Daniel P. Rossignol, Seiichi Kobayashi, Ieharu Hishinuma, Akifumi Kimura, Naoki Asakawa, Kouichi Katayama, and Isao Yamatsu, Science 268, 80 (1995). 
197. "Preferred Conformation of $C$-Glycosides. 14. Synthesis and Conformational Analysis of Carbon Analogs of the Blood Group Determinant H-Type II", Alexander Wei, Arnaud Haudrechy, Catherine Audin, Hyuk-Sang Jun, Nathalie Haudrechy-Bretel, and Yoshito Kishi, J. Org. Chem. 60, 2160 (1995).

198. "The Potencies of Synthetic Analogues of Saxitoxin and the Absolute Streochemistry of Decarbamoyl Saxitoxin", Gary R. Strichartz, Sherwood Hall, Barbarajean Magnani, Chang Yong Hong, Yoshito Kishi, and John A. DeBin, Toxicon 33, 723 (1995).

199. "Absolute Configuration at the Tricarballylic Acid Moieties of Fumonisin B2", Craig D. Boyle and Yoshito Kishi, Tetrahedron Lett. 36, 4579 (1995).

200. "Novel Syntheses Of $\beta$-Halo- $\alpha, \beta$-Unsaturated Ketones", Michael H. Kress and Yoshito Kishi, Tetrahedron Lett. 36, 4583 (1995).

201. "Absolute Configuration at the Tricarballylic Acid Moieties of Fumonisin B1 and AAL Toxin TA”, Craig D. Boyle and Yoshito Kishi, Tetrahedron Lett. 36, 5695 (1995).

202. "Ni(II)/Cr(II)-Mediated Coupling Reaction: An Asymmetric Process", Chinpiao Chen, Katsuya Tagami, and Yoshito Kishi, J. Org. Chem. 60, 5386 (1995).

203. "Biological Evaluation of Rationally Modified Analogs of the H-Type II Blood Group Trisaccharide. A Correlation between Solution Conformation and Binding Affinity", Alexander Wei, Kenneth M. Boy, and Yoshito Kishi, J. Am. Chem. Soc. 117, 9432 (1995).

204. "Novel, Light Emitting Reaction of (E)-2-benzenesulfonyl-3-phenyloxaziridine with Strong Bases", Milan N. Stojanovic and Yoshito Kishi, J. Am. Chem. Soc. 117, 9921 (1995).

205. "Interaction of Palytoxin with Red Cells: Structure-Funtion Studies", Magdalena T. Tosteson, David R. L. Scriven, Amitabh K. Bharadwaj, Yoshito Kishi, and Daniel C. Tosteson, Toxicon 33, 799 (1995).

206. "Specific Lipid A Analog Which Exhibits Exclusive Antagonism of Endotoxin", Tsutomu Kawata, John R. Bristol, Jeffrey R. Rose, Daniel P. Rossignol, William J. Christ, Osamu Asano, Gloria R. Dubuc, Wendy E. Gavin, Lynn D. Hawkins, Michael D. Lewis, Pamela D. McGuinness, Maureen A. Mullarkey, Michel Perez, Andrea L. C. Robidoux, Yuan Wang, Yoshito Kishi, Seiichi Kobayashi, Akifumi Kimura, Ieharu Hishinuma, Kouichi Katayama, and Isao Yamatsu, Novel Therapeutic Strategies in the Treatment of Sepsis, ed. David C. Morrison and John L. Ryan, pages 171-186, Marcel Dekker, New York (1995).

207. "Complete Relative Stereochemistry of Maitotoxin”, Wanjun Zheng, John A. DeMattei, Jiang-Ping Wu, James J.-W. Duan, Laura R. Cook, Hitoshi Oinuma, and Yoshito Kishi, J. Am. Chem. Soc. 118, 7946 (1996). 
208. "Total Synthesis and Stereochemistry of Cytoblastin", Ofir A. Moreno and Yoshito Kishi, J. Am. Chem. Soc. 118, 8180 (1996).

209. "Synthetic Studies on Halichondrins: A Practical Synthesis of the C.1-C.13 Segment", Dean P. Stamos and Yoshito Kishi, Tetrahedron Lett. 37, 8643 (1996).

210. “A Mild Preparation of Vinyliodides from Vinylsilanes", Dean P. Stamos, Andrew G. Taylor, and Yoshito Kishi, Tetrahedron Lett. 37, 8647 (1996).

211. "The Stereochemical Assignment and Conformational Analysis of the V/W-Ring Juncture of Maitotoxin", Laura R. Cook, Hitoshi Oinuma, Marcus A. Semones, and Yoshito Kishi, J. Am. Chem. Soc. 119, 7928 (1997).

212. "Enantioselective Total Synthesis of Fumonisin B2", Yan Shi, Lee F. Peng, and Yoshito Kishi, J. Org. Chem. 62, 5666 (1997).

213. "Ni(II)/Cr(II)-Mediated Coupling Reaction: Beneficial Effects of 4-tert-Butylpyridine as an Additive and Development of New and Improved Workup Procedures", Dean P. Stamos, X. Christopher Sheng, Sean S. Chen, and Yoshito Kishi, Tetrahedron Lett. 38, 6355 (1997).

214. "Extension of the Eschenmoser Sulfide Contraction/Iminoester Cyclization Method to the Synthesis of Tolyporphin Chromophore", Thomas G. Minehan and Yoshito Kishi, Tetrahedron Lett. 38, 6811 (1997).

215. " $\beta$-Selective $C$-Glycosidations: Lewis-Acid Mediated Reactions of Carbohydrates with Silyl Ketene Acetals", Thomas G. Minehan and Yoshito Kishi, Tetrahedron Lett. 38, 6815 (1997).

216. "New Synthetic Route to the C.14-C.38 Segment of Halichondrins", Dean P. Stamos, Sean S. Chen, and Yoshito Kishi, J. Org. Chem. 62, 7552 (1997).

217. "New, Flexible Synthesis of 1,4,5,6-Tetrahydrocyclopentapyrrol-4-ones", Milan N. Stojanovic and Yoshito Kishi, J. Serb. Chem. Soc. 62, 749 (1997).

218. "Total Synthesis of Altohyrtin A (Spongistatin 1): Part One”, Jiasheng Guo, Kevin J. Duffy, Kirk L. Stevens, Peter I. Dalko, Rebecca M. Roth, Matthew M. Hayward, and Yoshito Kishi, Angew. Chem. Int. Ed. Engl. 37, 187 (1998).

219. "Total Synthesis of Altohyrtin A (Spongistatin 1): Part Two", Matthew M. Hayward, Rebecca M. Roth, Kevin J. Duffy, Peter I. Dalko, Kirk L. Stevens, Jiasheng Guo, and Yoshito Kishi, Angew. Chem. Int. Ed. Engl. 37, 192 (1998). 
220. "Reaction of Methylcerium Reagent with Tertiary Amides: Synthesis of Saturated and Unsaturated Ketones from Tertiary Amides", Michio Kurosu and Yoshito Kishi, Tetrahedron Lett. 39, 4793 (1998).

221. “Complete Structure of Maitotoxin”, Y. Kishi, Pure Appl. Chem. 70, 339 (1998).

222. "The Structural Basis of Protein Kinase C Activation by Tumor Promoters", Yoshito Kishi and Robert R. Rando, Acc. Chem. Res. 31, 163 (1998).

223. "Total Synthesis of ( \pm )-Batrachotoxinin A”, Michio Kurosu, Lawrence R. Marcin, Timothy J. Grinsteiner, and Yoshito Kishi, J. Am. Chem. Soc. 120, 6627 (1998).

224. "Total Synthesis of Pinnatoxin A”, John A. McCauley, Kazuo Nagasawa, Peter A. Lander, Steven G. Mischke, Marcus A. Semones, and Yoshito Kishi, J. Am. Chem. Soc. 120, 7647 (1998).

225. "Total Synthesis and Stereochemistry of Cytoblastin", Ofir A. Moreno and Yoshito Kishi, Bioorg. Med. Chem. 6, 1243 (1998).

226. "A Novel Example For Optical Resolution of Racemic Ketones Originating From Batrachotoxin Synthesis”, Michio Kurosu and Yoshito Kishi, J. Org. Chem. 63, 6100 (1998).

227. "Experimental Support for the Primary Stereoelectronic Effect Governing BaeyerVilliger Oxidation and Criegee Rearrangement", Richard M. Goodman and Yoshito Kishi, J. Am. Chem. Soc. 120, 9392 (1998).

228. "A Useful Modification of the Garst-Spencer Furan Annulation: An Improved Synthesis of 3,4-Substituted Furans", Michio Kurosu, Lawrence R. Marcin, and Yoshito Kishi, Tetrahedron Lett. 39, 8929 (1998).

229. "Preferred Conformation of $C$-Lactose at the Free and Peanut-Lectin-Bound States", R. Ravishankar, A. Surolia, M. Vijayan, Sungtaek Lim, and Yoshito Kishi, J. Am. Chem. Soc. 120, 11297 (1998).

230. "Suppression of Murine Endotoxin Response by E5531, a Novel Synthetic Lipid A Antagonist”, Seiichi Kobayashi, Tsutomu Kawata, Akifumi Kimura, Kaname Miyamoto, Koichi Katayama, Isao Yamatsu, Daniel P. Rossignol, William J. Christ, and Yoshito Kishi, Antimicrob. Agents Chemoth. 42, 2824 (1998).

231. "Total Synthesis of the Proposed Structure of (+)-Tolyporphin A O,O-Diacetate", Thomas G. Minehan and Yoshito Kishi, Angew. Chem. Int. Ed. 38, 923 (1999).

232. "Revised Structure of Tolyporphin A", Thomas G. Minehan, Laura Cook-Blumberg, Yoshito Kishi, Michèle R. Prinsep, and Richard E. Moore, Angew. Chem. Int. Ed. 38, 926 (1999). 
233. "Covalently Cross-Linked Watson-Crick Base Pair Models", Xiaoxin Qiao and Yoshito Kishi, Angew. Chem. Int. Ed. 38, 928 (1999).

234. "Synthesis and Structure of Tolyporphin A $O, O$-Diacetate", Wengui Wang and Yoshito Kishi, Org. Lett. 1, 1129 (1999).

235. "Toward Creation of a Universal NMR Database for the Stereochemical Assignment of Acyclic Compounds: The Case of Two Contiguous Propionate Units", Yoshihisa Kobayashi, Jinhwa Lee, Kenichi Tezuka, and Yoshito Kishi, Org. Lett. 1, 2177 (1999).

236. "Toward Creation of a Universal NMR Database for the Stereochemical Assignment of Acyclic Compounds: Proof of Concept", Jinhwa Lee, Yoshihisa Kobayashi, Kenichi Tezuka, and Yoshito Kishi, Org. Lett. 1, 2181 (1999).

237. "Toward Creation of a Universal NMR Database for Stereochemical Assignment: The Case of 1,3,5-Trisubstituted Acyclic Systems “, Yoshihisa Kobayashi, Choon-Hong Tan, and Yoshito Kishi, Helv. Chim. Acta 83, 2562 (2000).

238. "Stereochemical Assignment of the C.21-C.38 Portion of the Desertomycin/Oasomycin Class of Natural Products via Universal NMR Databases: Prediction “, Yoshihisa Kobayashi, Choon-Hong Tan, and Yoshito Kishi, Angew. Chem. Int. Ed. 39, 4279 (2000).

239. "Stereochemical Assignment of the C.21-C.38 Portion of the Desertomycin/Oasomycin Class of Natural Products via Universal NMR Databases: Proof “, Choon-Hong Tan, Yoshihisa Kobayashi, and Yoshito Kishi, Angew. Chem. Int. Ed. 39, 4282 (2000).

240. "Structure-Activity Relationships of Halichondrin B Analogues: Modification at C.30C.38”, Yuan Wang, Greg J. Habgood, William J. Christ, Yoshito Kishi, Bruce A. Littlefield, and Melvin J. Yu, Bioorg. Med. Chem. Lett. 10, 1029 (2000).

241. “Covalently Cross-Linked Watson-Crick Base Pair Models. 2.", Yao-Ling Qiu, HongYu Li, George Topalov, and Yoshito Kishi, Tetrahedron Lett. 41, 9425 (2000).

242. "Synthesis of DNA-Oligomers Possessing a Covalently Cross-Linked Watson-Crick Base Pair Model”, Hong-Yu Li, Yao-Ling Qiu, Elisabeth Moyroud, and Yoshito Kishi, Angew. Chem. Int. Ed. 40, 1471 (2001).

243. "In Vitro and In vivo Anticancer Activities of Synthetic Macrocyclic Ketone Analogues of Halochondrin B”, Murray, J. Towel, Kathleen A. Salvato, Jacqueline Budrow, Bruce F. Wels, Galina Kuznetsov, Kimberley K. Aalfs, Susan Welsh, Wanjun Zheng, Boris M. Seletsky, Monica H. Palme, Gregory J. Habgood, Lori A. Singer, Lucian V. DiPietro, Yuan Wang, Jack J. Chen, David A. Quincy, Ashley Davis, Kentaro Yoshimatsu, Yoshito Kishi, Melvin J. Yu, and Bruce A. Littlefield, Cancer Res. 61, 1013 (2001). 
244. "Toward Creation of a Universal NMR Database for Stereochemical Assignment: Complete Structure of the Desertomycin/Oasomycin Class of Natural Products", Yoshihisa Kobayashi, Choon-Hong Tan, and Yoshito Kishi, J. Am. Chem. Soc. 123, 2076 (2001).

245. "Solution Structure of $n$-type DNA-Oligomers Possessing a Covalently Cross-Linked Watson-Crick Base Pair Model”, Hong-Yu Li, Yao-Ling Qiu, and Yoshito Kishi, ChemBioChem. 2, 371 (2001).

246. "Stereochemistry of the Core Structure of the Mycolactones", Andrew B. Benowitz, Steve Fidanze, P. L. C. Small, and Yoshito Kishi, J. Am. Chem. Soc. 123, 5128 (2001).

247. "Toward Creation of NMR Databases in Chiral Solvents for Assignments of Relative and Absolute Stereochemistry: Proof of Concept", Yoshihisa Kobayashi, Nobuyuki Hayashi, Choon-Hong Tan, and Yoshito Kishi, Org. Lett. 3, 2245 (2001).

248. "Toward Creation of NMR Databases in Chiral Solvents for Assignments of Relative and Absolute Stereochemistry: Scope and Limitation", Nobuyuki Hayashi, Yoshihisa Kobayashi, and Yoshito Kishi, Org. Lett. 3, 2249 (2001).

249. "Toward Creation of NMR Databases in Chiral Solvents for Assignments of Relative and Absolute Stereochemistry: NMR Desymmetrization of meso-Compounds", Yoshihisa Kobayashi, Nobuyuki Hayashi, and Yoshito Kishi, Org. Lett. 3, 2253 (2001).

250. "Chlorophyll Catabolism Leading to the Skeleton of Dinoflagellate and Krill Luciferins: Hypothesis and Model Studies", George Topalov and Yoshito Kishi, Angew. Chem. Int. Ed. 40, 3892 (2001).

251. "Complete Structure of the Mycolactones", Steve Fidanze, Fengbin Song, Magali Szlosek-Pinaud, P. L. C. Small, and Yoshito Kishi, J. Am. Chem. Soc. 123, 10117 (2001).

252. "Toward the Creation of NMR Databases in Chiral Solvents: Bidentate Chiral NMR Solvents for Assignment of the Absolute Configuration of Acyclic Secondary Alcohols", Yoshihisa Kobayashi, Nobuyuki Hayashi, and Yoshito Kishi, Org. Lett. 4, 411 (2002).

253. "Total Synthesis of the Mycolactones", Fengbin Song, Steve Fidanze, Andrew B. Benowitz, and Yoshito Kishi, Org. Lett. 4, 647 (2002).

254. "Palytoxin: An Inexhaustible Source Of Inspiration-Personal Perspective-", Yoshito Kishi, Tetrahedron, 58, 6239 (2002).

255. "Synthesis of the C20-C26 Building Block of Halichondrins via a Regiospecific and Stereoselective $\mathrm{S}_{\mathrm{N}} 2$ ' Reaction”, Chaoyu Xie, Pawel Nowak, and Yoshito Kishi, Org. Lett. 4, 4427 (2002). 
256. “Asymmetric Ni(II)/Cr(II)-mediated Coupling Reaction: Stoichiometric Process”, ZhaoKui Wan, Hyeong-wook Choi, Fu-An Kang, Katsumasa Nakajima, Damtew Demeke, and Yoshito Kishi, Org. Lett. 4, 4431 (2002).

257. “Asymmetric Ni(II)/Cr(II)-mediated Coupling Reaction: Catalytic Process”, Hyeongwook Choi, Katsumasa Nakajima, Damtew Demeke, Fu-An Kang, Hyuk-Sang Jun, Zhao-Kui Wan, and Yoshito Kishi, Org. Lett. 4, 4435 (2002).

258. "Complete Stereochemistry of Tetrafibricin”, Yoshihisa Kobayashi, Werngard Czechtizky, and Yoshito Kishi, Org. Lett. 5, 93 (2003).

259. "Synthetic Studies on the Marine Natural Products Halichondrins", H. Choi, D. Demeke, F.-A. Kang, Y. Kishi, K. Nakajima, P. Nowak, Z.-K. Wan, and C. Xie, Pure Appl. Chem. 75, 1 (2003).

260. "Conformational Analysis of $C$-Glycosides and Related Compounds: Programming Conformational Profiles of $C$ - and $O$-Glycosides", Peter G. Goekjian, Alexander Wei, and Yoshito Kishi, in Carbohydrate-based Drug Discovery, Ed. Chi-Huey Wong, WileyVCH, Weinheim, Germany, 2003.

261. "Synthetic Lipid-A Antagonists for Sepsis Treatment “, William J. Christ, Lynn D. Hawkins, Michael D. Lewis, and Yoshito Kishi, in Carbohydrate-based Drug Discovery, Ed. Chi-Huey Wong, Wiley-VCH, Weinheim, Germany, 2003.

262. "Application of Chiral Bidentate NMR Solvents for Assignment of the Absolute Configuration of Alcohols: Scope and Limitation", Yoshihisa Kobayashi, Nobuyuki Hayashi, Yoshito Kishi, Tetrahedron Lett., 44, 7489 (2003).

263. "Universal NMR Databases for Contiguous Polyols", Shuhei Higashibayashi, Werngard Czechtizky, Yoshihisa Kobayashi, and Yoshito Kishi, J. Am. Chem. Soc. 125, 14379 (2003).

264. "A Simple but Remarkably Effective Device to Form the C8-C14 Polycyclic Ring System of Halichondrin B", Kosuke Namba, Hyuk-Sang Jun, and Yoshito Kishi, J. Am. Chem. Soc. 126, 7770 (2004).

265. "Assignment of the relative and absolute configurations of acyclic secondary 1,2-diols", Shuhei Higashibayashi and Yoshito Kishi, Tetrahedron 60, 11977 (2004).

266. "Fe/Cr- and Co/Cr-Mediated Catalytic Asymmetric 2-Haloallylations of Aldehydes", Michio Kurosu, Mei-Huey Lin, and Yoshito Kishi, J. Am. Chem. Soc. 126, 12248 (2004).

267. "Induction of Morphological and Biochemical Apoptosis following Prolonged Mitotic Blockage by Halichondrin B Macrocyclic Ketone Analog E7389”, Galina Kuznetsov, Murray J. Towle, Hongsheng Cheng, Takanori Kawamura, Karen TenDyke, Diana Liu, Yoshito Kishi, Melvin J. Yu, and Bruce A. Littlefield, Cancer Res. 64, 5760 (2004). 
268. “Discovery of E7389, a Fully Synthetic Macrocyclic Ketone Analog of Halichondrin B”, Melvin J. Yu, Yoshito Kishi, Bruce A. Littlefield,

269. "Structurally Simplified Macrolactone Analogues of Halichondrin B", Boris M. Seletsky, Yuan Wang, Lynn D. Hawkins, Monica H. Palme, Gregory J. Habgood, Lucian V. DiPietro, Murray J. Towle, Kathleen A. Salvato, Bruce F. Wels, Kimberley K. Aalfs, Yoshito Kishi, Bruce A. Littlefield, and Melvin J. Yu, Bioorg. Med. Chem. Lett. 14, 0000 (2004).

270. "Macrocyclic Ketone Analogues of Halichondrin B", Wanjun Zheng, Boris M. Seletsky, Monica H. Palme, Paul J. Lydon, Lori A. Singer, Charles E. Chase, Charles A. Lemelin, Yongchun Shen, Heather Davis, Lynda Tremblay, Murray J. Towle, Kathleen A. Salvato, Bruce F. Wels, Kimberley K. Aalfs, Yoshito Kishi, Bruce A. Littlefield, and Melvin J. Yu, Bioorg. Med. Chem. Lett. 14, 0000 (2004).

271. "Application of Chiral Lanthanide Shift Reagents for Assignment of Absolute Configuration of Alcohols", Indranath Ghosh, Hongbo Zeng, and Yoshito Kishi, Org. Lett. 6, 4715 (2004).

272. "Use of a Chiral Praseodymium Shift Reagent in Predicting the Complete Stereostructure of Glisoprenin A", Indranath Ghosh, Yoshito Kishi, Hiroshi Tomoda, and Satoshi Omura, Org. Lett. 6, 4719 (2004).

273. "Validation of Lanthanide Chiral Shift Reagents for Determination of Absolute Configuration: Total Synthesis of Glisoprenin A", Christopher M. Adams, Indranath Ghosh, and Yoshito Kishi, Org. Lett. 6, 4723 (2004).

274. "Structure Determination of Mycolactone C via Total Synthesis", Ted C. Judd, Alexander Bischoff, Yoshito Kishi, Sarojini Adusumilli, and Pam L. C. Small, Org. Lett. 6, 4901 (2004).

275. "New Catalytic Cycle for Couplings of Aldehydes with Organochromium Reagents", Kosuke Namba and Yoshito Kishi, Org. Lett. 6, 5031 (2004).

276. "Studies on the Total Synthesis of Batrachotoxin", MichioKurosu and Yoshito Kishi, $J$. Synth. Org. Chem., Jpn, 62, 1205 (2004).

277. "A Biomimetic Macrocycle-Forming Diels-Alder Reaction of an Iminium Dienophile: Synthetic Studies Directed Towards Gymnodimine", Jeffrey W. Johannes, Steve Wenglowsky, and Yoshito Kishi, Org. Lett. 7, 3997 (2005).

278. "A New Method for Translating the Asymmetric Ni/Cr-Mediated Coupling Reactions from Stoichiometric to Catalytic”, Kosuke Namba, Sheng Cui, Jiashi Wang, and Yoshito Kishi Kishi, Org. Lett. 7, 5417 (2005). 
279. “Surprisingly Efficient Catalytic Cr-Mediated Coupling Reactions”, Kosuke Namba, Jiashi Wang, Sheng Cui, and Yoshito Kishi, Org. Lett. 7, 5421 (2005).

280. “Catalytic Ni/Cr-Mediated Macrocyclization Without Use of High-Dilution Techniques", Kosuke Namba and Yoshito Kishi, J. Am. Chem. Soc. 127, 15382 (2005).

281. "Unified Total Synthesis of Pteriatoxins and their Diastereomers", Fumiyoshi Matsuura, René Peters, Masahiro Anada, Scott S. Harried, Junliang Hao, and Yoshito Kishi, J. Am. Chem. Soc. 128, 7463 (2006).

282. "Stereochemistry of Pteriatoxins A, B, and C", Junliang Hao, Fumiyoshi Matsuura, Yoshito Kishi, Masaki Kita, Daisuke Uemura, Naoki Asai, Takashi Iwashita, J. Am. Chem. Soc. 128, 7742 (2006).

283. "Total Synthesis and Stereochemistry of Pinnatoxins B and C”, Fumiyoshi Matsuura, Junliang Hao, Reinhard Reents, and Yoshito Kishi, Org. Lett. 8, 3327 (2006).

284. "Attempts to Assemble Universal NMR Database without Synthesis of NMR Database Compounds", Hirofumi Seike, Indranath Ghosh, and Yoshito Kishi, Org. Lett. 8, 3861 (2006).

285. "Stereochemistry of Sagittamide A: Prediction and Confirmation", Hirofumi Seike, Indranath Ghosh, and Yoshito Kishi, Org. Lett. 8, 3865 (2006).

286. "Synthetic 3-O-Methylmannose-containing Polysaccharides ( $s$ MMP): Design and Synthesis", Margaret C. Hsu, Jinhwa Lee, and Yoshito Kishi, submitted for publication.

287. "Synthetic 6-O-Methylglucose-containing Polysaccharides ( $s$ MGP): Design and Synthesis", Malte Meppen, Yonghui Wang, Hwan-Sung Cheon, and Yoshito Kishi, submitted for publication.

288. “Aggregation Behaviors of Tetraenoic Fatty Acids in Aqueous Solution”, Yonghui Wang, Jianguo Ma, Hwan-Sung Cheon, and Yoshito Kishi, submitted for publication.

289. "Complexation of Fatty Acids and Fatty Acids-CoAs with Synthetic $O$-Methylated Polysaccharides", Hwan-Sung Cheon, Yonghui Wang, Jianguo Ma, and Yoshito Kishi, submitted for publication.

290. "Chiral Aggregates Formed from Methylated Tetraenoic Fatty Acids: Formation of Both Antipodes of Chiral Aggregates from a Single Enantiomer and Stereomutation", Jianguo Ma, Hwan-Sung Cheon, and Yoshito Kishi, submitted for publication. 